\title{
LitR, a new transcriptional activator in Vibrio fischeri, regulates luminescence and symbiotic light organ colonization
}

Pat M. Fidopiastis, Carol M. Miyamoto, Michael G. Jobling, Edward A. Meighen and Edward G. Ruby
Introduction

An increasing awareness of the role that benign bacterial associations play in the normal development and health of animals has driven an interest in the mechanisms by which a host initially obtains and subsequently maintains its specific bacterial symbionts (McFall-Ngai, 1999; Hooper and Gordon, 2001). Within hours of hatching, juveniles of the squid Euprymna scolopes acquire within the epithelium-lined crypts of their nascent light organ a monospecific population of the luminous bacterium Vibrio fischeri. This symbiotic infection initially stabilizes at a level of about $5 \times 10^{5}$ cells, but eventually reaches about $10^{9}$ cells in the fully grown adult (Ruby and Asato, 1993). Within the crypt spaces of the light organ, $V$. fischeri cells induce their lux genes, which results in the emission of a bright luminescence that is believed to assist the squid in its nocturnal activities (McFall-Ngai, 1990). During the first few hours to days following this benign infection, a number of morphological changes occur in the polarized epithelial cells lining the light organ crypts, e.g. both the volume and the microvillar density of the cells increase fourfold, and they become more cuboidal in shape (McFall-Ngai, 1994; Lamarcq and McFall-Ngai, 1998). These changes are triggered only in the presence of $\mathrm{V}$. fischeri cells and presumably enhance the intimacy of the symbionts with one another and with the crypt epithelium.

The light organ is a dynamic environment for the bacteria: each morning, about $95 \%$ of the $V$. fischeri population is vented into the surrounding sea water, leaving the remaining $5 \%$ to repopulate the organ by the subsequent nightfall (Lee and Ruby, 1994a). The ability to induce this venting behaviour experimentally has facilitated morphological and biochemical analyses of the light organ contents (Graf and Ruby, 1998; Nyholm and McFall-Ngai, 1998). Graf and Ruby (1998) concluded that the dense material surrounding the bacteria within the crypts consists largely of peptides that are capable of supporting the growth of auxotrophic mutants of $V$. fischeri. In addition, before entering the external pores that lead into the crypts, $V$. fischeri cells in the ambient sea water must aggregate on and move through a mucous matrix produced by the host (Nyholm et al., 2000).

Recent results have begun to identify bacterial activities such as catalase and bioluminescence that are 
required for successful colonization and/or the initiation of host development (Visick and McFall-Ngai, 2000). Preliminary evidence (Fidopiastis and Ruby, 1999) has suggested that $V$. fischeri produces an extracellular proteolytic activity similar to that exhibited by the Vibrio cholerae Hap (Finkelstein et al., 1983), Vibrio vulnificus Vvp (Nishina et al., 1992) or Vibrio anguillarum EmpA (Garcia et al., 1997) proteins. This activity might allow symbiosis-competent cells of $V$. fischeri to (i) move through the mucous barrier outside the light organ pores (Nyholm et al., 2000) and/or (ii) gain access to hostderived peptides in the crypts (Graf and Ruby, 1998). The expression of all three of these other Vibrio spp. proteases has been shown to be dependent on TetR family regulator proteins [i.e. HapR (Jobling and Holmes, 1997); SmcR (McDougald et al., 2001; Shao and Hor, 2001); and VanT (Milton et al., 1999) respectively]. In addition, two other homologues have been described: OpaR, which controls colony opacity in Vibrio parahaemolyticus (McCarter, 1998), and LuxR, which is required for luminescence in Vibrio harveyi (Showalter et al., 1990). To date, there have been no reports of a homologous regulatory protein in $V$. fischeri. To understand better the control of both protease activity and luminescence in V. fischeri, and to examine how these activities might be modulated in the symbiosis, we searched for a gene that might encode a member of this family of regulators.

We report here the discovery in $V$. fischeri of litR, a gene that encodes a protein with high sequence identity to the other TetR family transcriptional regulators present in Vibrio spp. Its product, designated LitR, not only has functional characteristics that are like those reported for some of the other homologues, but also an unexpected activity. Specifically, we provide evidence that LitR is important for the normal induction of luminescence, and also plays a novel role in modulating the ability of $V$. fischeri to colonize juvenile squid.

\section{Results}

Homology of litR to other regulatory proteins in Vibrio species

Using degenerate primers based on highly conserved coding regions between the $V$. cholerae hap $R$ and the $V$. harveyi lux $R$ gene sequences, a $255 \mathrm{bp}$ product was amplified from eight strains of $V$. fischeri isolated from diverse sources, as well as from two Vibrio logei strains (Fig. 1). No product was obtained from the slightly more distantly related species Photobacterium profundum SS9. The peptide encoded by the polymerase chain reaction (PCR) product from V. fischeri strain ES114 was 67\% identical to that encoded by the corresponding region of $V$. cholerae hapR. Using this PCR product as a probe, the complete litR gene was detected within a $12 \mathrm{~kb}$ EcoRI fragment of $V$. fischeri strain ES114 genomic DNA and further localized to a $3 \mathrm{~kb}$ Sacl-Clal fragment. The $3 \mathrm{~kb}$ fragment was sequenced, and a putative ribosome-binding sequence 'AAGGA' was detected 9 bases upstream of the start of the predicted open reading frame (ORF); however, we did not find consensus -35 (TTGACC) or -10 (TACACT) sequences to be present in
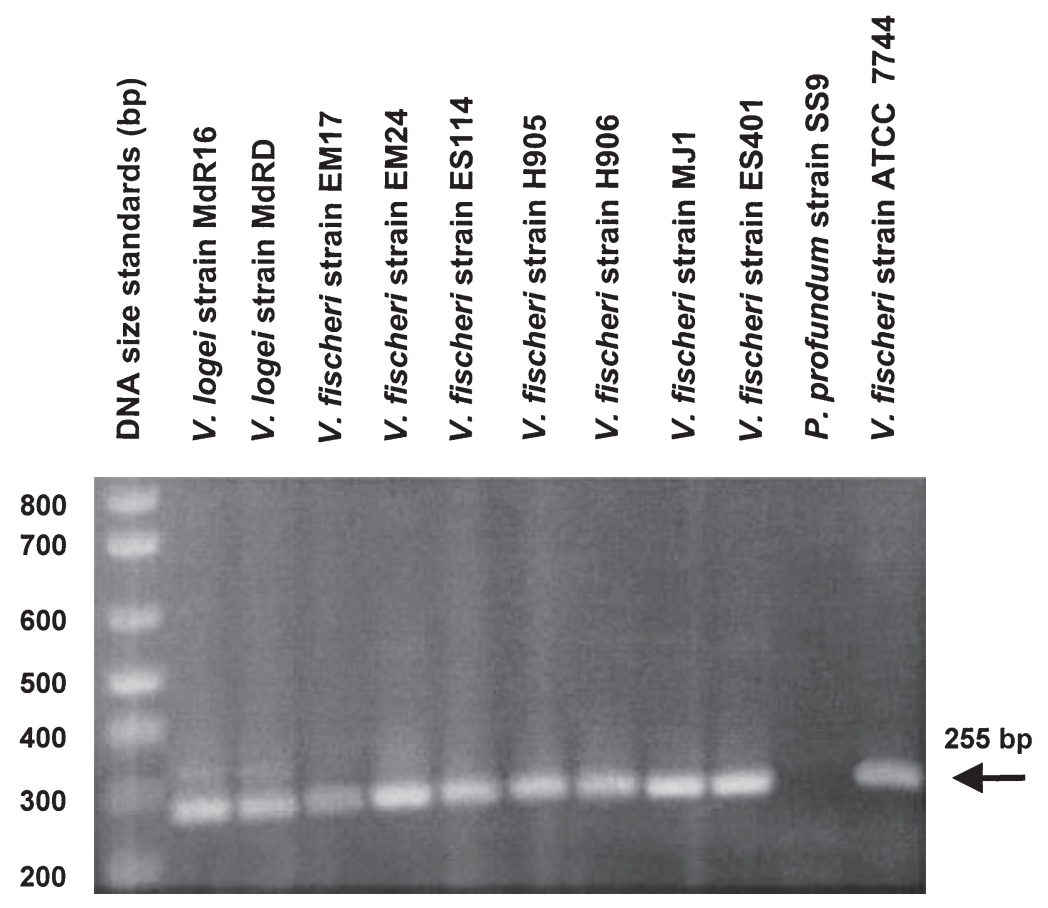

Fig. 1. PCR amplification of a fragment of a $V$. cholerae hapR homologue from strains of $V$. fischeri and $V$. logei. PCR primers recognizing $V$. cholerae hap $R$ sequences were mixed in a PCR with genomic DNA from a number of strains, and a product of the indicated size was amplified. V. logei MdR16 and MdRD are sea-water isolates from southern California; V. fischeri EM17 and EM24 are light organ symbionts of Euprymna morsei (Ruby and Asato, 1993); V. fischeri ES114 and ES401 are light organ symbionts of Euprymna scolopes (Boettcher and Ruby, 1994); V. fischeri $\mathrm{H} 905$ and $\mathrm{H} 906$ are sea-water isolates from Kaneohe Bay, Hawaii (Lee and Ruby, 1994); V. fischeri MJ1is a light organ symbiont of Monocentris japonica (Ruby and Nealson, 1976); and P. profundum SS9 is a deep-ocean sea-water isolate (Welch and Bartlett, 1998). 


\begin{tabular}{|c|c|c|c|c|c|c|}
\hline HapR & MDASIEKRPR & TRLSPQKRKL & QLMEIALEVF & AKRGIGRGGH & ADIAEIAQVS & \\
\hline LuxR & . MDS IAKRPR & TRLSPLKRKQ & QLMEIALEVF & ARRGIGRGGH & $\overline{\mathrm{AD}} I A E I A Q V S$ & \\
\hline OpaR & . MDS IAKRPR & TRLSPLKRKQ & QLMEIALEVF & ARRGIGRGGH & ADIAEIAQVS & \\
\hline SmcR & . MDSIAKRPR & TRLSPLKRKQ & QLMEIALEVF & ARRGIGRGGH & ADIAEIAQVS & \\
\hline LitR & .MDTIQKRPR & TRLSPEKRKE & QLLDIAIEVF & SQRGIGRGGH & ADIAEIAQVS & \\
\hline 51 & 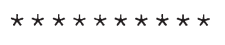 & 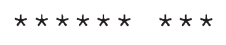 & * & $\star \star \star \star$ & $\star$ & 100 \\
\hline HapR & VATVFNYFPT & REDLVDDVLN & FVVRQYSNFL & TDHIDLDLDV & KTNLQTVCKE & \\
\hline LuxR & VATVFNYFPT & REDLVDEVLN & HVVRQFSNFL & SDNIDLDIHA & RENIANITNA & \\
\hline OpaR & VATVFNYFPT & REDLVDEVLN & HVVRQFSNFL & SDNIDLDIHA & RENIANITNA & \\
\hline SmcR & VATVFNYFPT & REDLVDEVLN & HVVRQFSNFL & SDNIDLDLHA & KENIANITNA & \\
\hline LitR & VATVFNYFPT & REDLVDDVLN & KVENEFHQFI & NNSISLDLDV & RSNLNTLLLN & \\
\hline 101 & & 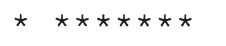 & 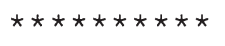 & * & $\star \star$ & 150 \\
\hline HapR & MVKLAMTDCH & WLKVWFEWSA & STRDEVWPLF & VSTNRTNQLL & IRNMFMKAME & \\
\hline LuxR & MIELVSQDCH & WLKVWFEWSA & STRDEVWPLF & VTTNRTNQLL & VQNMFIKAIE & \\
\hline OpaR & MIELVSQDCH & WLKVWFEWSA & STRDEVWPLF & VSTNRTNQLL & VQNMFIKAIE & \\
\hline SmcR & MIELVVQDNH & WLKVWFEWSA & STRDEVWPLF & VTTNRTNQLL & VQNMFIKAIE & \\
\hline LitR & IIDSVQTGNK & WIKVWFEWST & STRDEVWPLF & LSTHSNTNQV & IKTMFEEGIE & \\
\hline 151 & 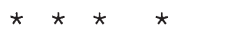 & $\star \star *$ & $\star * \star \star * * *$ & & $\star \star \star \star \star \star *$ & 200 \\
\hline HapR & RGELCEKHDV & DNMASLFHGI & FYSIFLQVNR & LGEQEAVYKL & ADSYLNMLCI & \\
\hline LuxR & RGEVCDQHEP & EHLANLFHGI & CYSIFVQANR & SKSEAELTNL & VSAYLDMLCI & \\
\hline OpaR & RGEVCDQHDS & EHLANLFHGI & CYSLFVQANR & FKGEAELKEL & VSAYLDMLCI & \\
\hline SmcR & RGEVCDQHNP & EDLANLFHGI & CYSLFVQANR & TNNTAELSKL & VSSYLDMLCI & \\
\hline LitR & RNEVCNDHTP & ENLTKMLHGI & CYSVFIQANR & NSSSEEMEET & ANCFLNMLCI & \\
\hline 201 & * & & & & & \\
\hline HapR & YKN . . & & & & & \\
\hline LuxR & YNREHH & & & & & \\
\hline OpaR & YNREH. & & & & & \\
\hline SmcR & YKREHE & & & & & \\
\hline LitR & YK. & & & & & \\
\hline
\end{tabular}

Fig. 2. Amino acid sequence alignment of LitR homologues. Residues that are conserved in all the five proteins are marked with an asterisk. Residues that are encoded by the nucleotides used to construct the degenerate PCR primers are underlined. Numbering refers to the residue order in the HapR molecule.

the same location as the promoter regions of hapR, luxR, opaR and smcR (Shao and Hor, 2001).

The litR sequence aligned across its entire coding region with the sequences of hapR, luxR, opaR and $s m c R$. In addition, partial sequences of the ORFs flanking litR shared significant (>80\%) identity to the hpt (5' of litR) and Ipd ( $3^{\prime}$ of litR) genes of $V$. parahaemolyticus. The litR gene encodes a 201-amino-acid protein that shares significant identity (58-60\%) with HapR, V. harveyi LuxR, V. parahaemolyticus OpaR and V. vulnificus SmcR (Fig. 2). The amino-terminal domain residues (numbers 6-69) share particularly high identity, with over $90 \%$ conserved in the other homologues. In addition, this region showed significant conservation when compared with a consensus sequence derived from the helix-turn-helix (HTH) DNA-binding domain of genes in the TetR family of negative transcriptional regulators. A phylogenetic comparison of the amino acid sequences of the homologues revealed them all to be within the TetR family of regulatory proteins (Fig. 3). LuxR, OpaR and SmcR form the most closely related grouping, whereas LitR appeared to have branched off earliest during the evolution of the Vibrio clade of TetR proteins.

\section{Luminescence defect in the litR mutant strain PMF8}

The growth rates of ES114 and PMF8 were essentially the same when cells were cultured in SWT medium at $28^{\circ} \mathrm{C}$, and PMF8 grew only slightly more slowly at $22^{\circ} \mathrm{C}$ (data not shown). Interestingly, under either of these growth conditions, PMF8 produced no detectable luminescence until the culture reached an optical density (OD) at $600 \mathrm{~nm}$ of $>1.2$. In contrast, the parent strain ES114 always induced luminescence at or before an OD of 1.0 


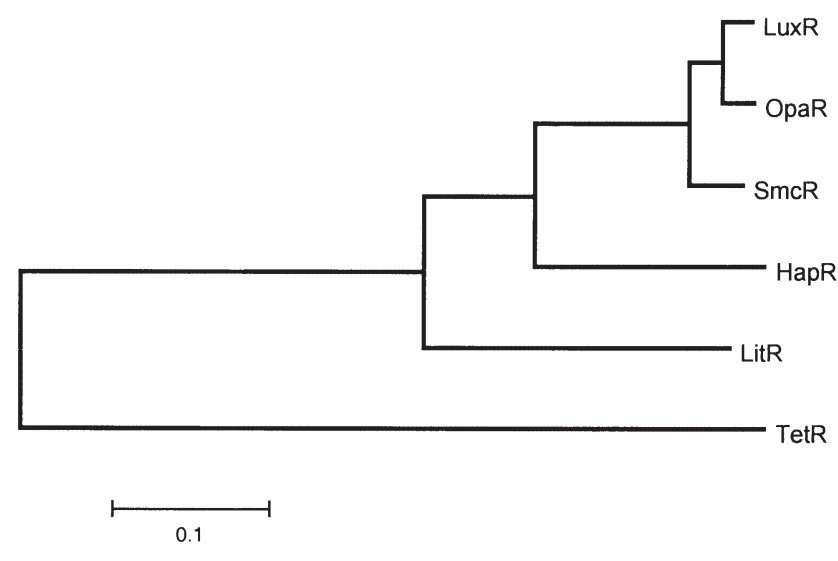

(Fig. 4). Subsequently, the level of luminescence (per cell) emitted by PMF8 remained $<20 \%$ that of ES114. This phenotypic defect could be relieved by the addition of a wildtype copy of either litR or $V$. harveyi lux $R$ carried in trans (Table 1). These data confirm that litR is responsible for the luminescence defect, and that $V$. harveyi lux $R$ can not only functionally complement the lit $R$ mutation but also, on a multicopy plasmid, leads to a level of luminescence expression that was even greater than that produced by the wild-type strain. In contrast, the presence of pMF2, which encodes a wild-type copy of litR, could not restore luminescence to a $V$. harveyi luxR mutant (data not shown).

\section{Regulation of luminescence by LitR enhancement of} V. fischeri luxR expression

To determine how the litR::Kan mutation results in a depression of the onset of light emission, we first asked whether the normal pattern of luminescence could be
(V. harveyi)

(V. parahaemolyticus)

(V. vulnificus)

(V. cholerae)

(V. fischeri)

(S. enterica)
Fig. 3. Phylogenetic tree constructed from the amino acid sequences of LitR and five of its homologues using the neighbour-joining method (Saitou and Nei, 1987). The homologues are found in $V$. harveyi (LuxR), V. parahaemolyticus (OpaR), V. vulnificus (SmcR), V. cholerae (HapR), V. fischeri (LitR) and Salmonella enterica (TetR). Calculated evolutionary distances are based on the 'p-distance' or the proportion of amino acid sites at which two sequences differ. The bar indicates a p-distance of 0.1 . restored by the addition of either the aliphatic aldehyde decanal (a substrate of the luciferase reaction) or the $V$. fischeri quorum-sensing autoinducer 3-oxo-hexanoyl homoserine lactone (VAI-1). Supplementing cultures with decanal did not fully restore luminescence of PMF8 to the levels emitted by the wild type, ES114 (Fig. 4). Instead, the addition of aldehyde stimulated luminescence proportionally, with PMF8 cells continuing to emit on average $<20 \%$ of the luminescence of ES114 cells. Similarly, although the addition of VAl-1 greatly enhanced light emission of both PMF8 and ES114, it did not fully restore PMF8 luminescence to the level emitted by strain ES114 grown in the presence of VAl-1 (Fig. 5). In fact, when compared with the wild-type parent, the absence of a functional lit $R$ resulted in a significant delay in the response of PMF8 to either VAl-1 (Fig. 5) or VAl-1 and aldehyde together (data not shown). We interpreted these data to suggest that this small but reproducible difference indicates that the mutant lit $R$ allele does not act simply through a direct effect on the levels of either of these

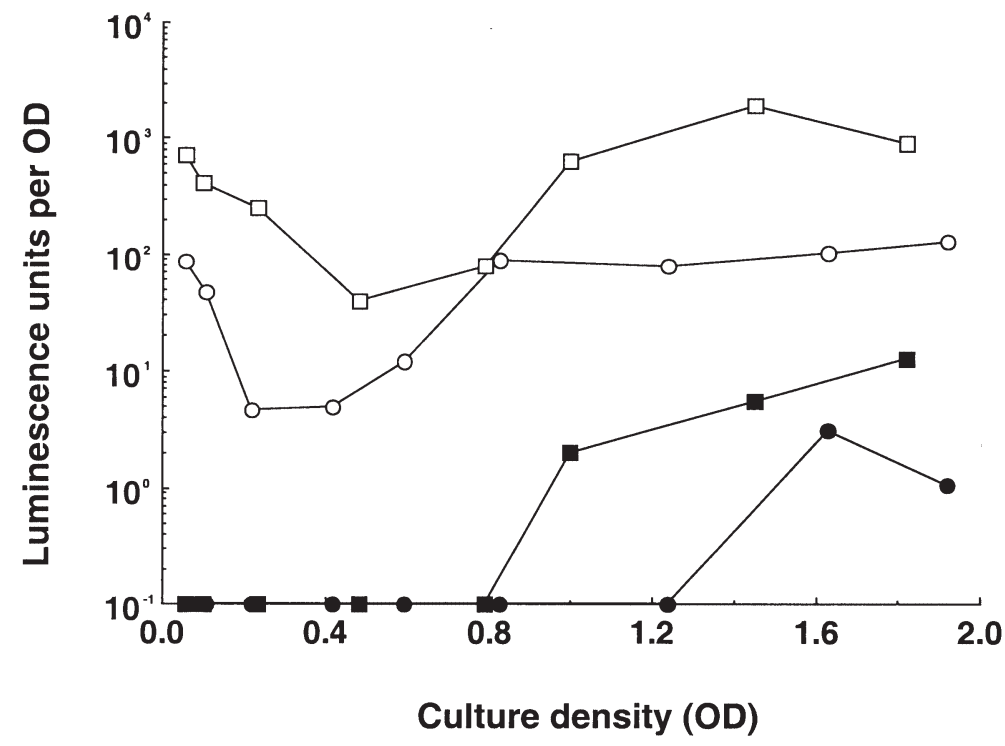

Fig. 4. Luminescence patterns of cells of $V$. fischeri strain ES114 (squares) and strain PMF8 (circles), with (open symbols) or without (closed symbols) exposure to decanal. At regular intervals, an aliquot of each culture was removed and measured for both $\mathrm{OD}$ and luminescence. Decanal was then added to the aliquot, and the level of luminescence was remeasured. One luminescence unit equals $1.3 \times 10^{4}$ quanta s${ }^{-1} \mathrm{ml}^{-1}$. Similar data were obtained in two other experiments. 
Table 1. Complementation of the luminescence defect in PMF8.

\begin{tabular}{|c|c|}
\hline Strain (with complementing plasmid) & $\begin{array}{l}\text { Luminescence } \\
\text { units per } O D^{a}\end{array}$ \\
\hline ES114 $\left(\right.$ litR $\left.{ }^{+}\right)$ & 3.5 \\
\hline PMF8 (litR $\left.{ }^{-}\right)$ & $<0.1$ \\
\hline PMF8 (with pMF2; litR ${ }^{+}$) & 30 \\
\hline PMF8 (with pVO8 ${ }^{b}$ ) & $<0.1$ \\
\hline PMF8 (with pMGM150; lux $R^{+c}$ ) & 40 \\
\hline
\end{tabular}

a. Measurements made on cultures at an OD of 1.0; one luminescence unit equals $1.3 \times 10^{4}$ quanta s$~^{-1} \mathrm{ml}^{-1}$.

b. pVO8 is the parent vector of pMF2.

c. V. harveyi luxR.

components of the luminescence system in $V$. fischeri. Instead, these data were consistent with the notion that the wild-type allele of litR enhances expression of the $V$. fischeri luxR gene (note that although they have the same gene name, $V$. fischeri lux $R$ and $V$. harveyi luxR, the $V$. fischeri litR homologue, encode completely unrelated proteins). We reasoned that, by increasing the basal level of the $V$. fischeri LuxR, the presence of a functional LitR might lead to a more rapid induction of luminescence in response to added VAl-1. In support of this hypothesis, expression of litR in trans led to a four- to fivefold increase in the expression of $\beta$-galactosidase from the $V$. fischeri luxR promoter (Table 2) when assayed in an Escherichia coli strain carrying pJE455 (luxR::lacZ). No such enhancement by LitR of the expression of the luxICDABE operon was noted by a similarly constructed luxC::lacZ fusion (Table 2). Furthermore, mobility shift analyses indicated that LitR binds to a $427 \mathrm{bp} B s t \mathrm{Bl}-P$ vull fragment that includes the $5^{\prime}$ region of the lux $R$ coding sequence and the complete luxR promoter region (Fig. 6).

\section{Other phenotypes affected by the litR mutation}

Colonies of $V$. fischeri ES114 grown on SWT agar medium are normally golden yellow and opaque. In contrast, colonies of PMF8 are almost entirely translucent, except for a slight opacity in the centre of the colony. This appearance is similar to that reported for colonies of an SmcR mutant strain of $V$. vulnificus (Shao and Hor, 2001). These

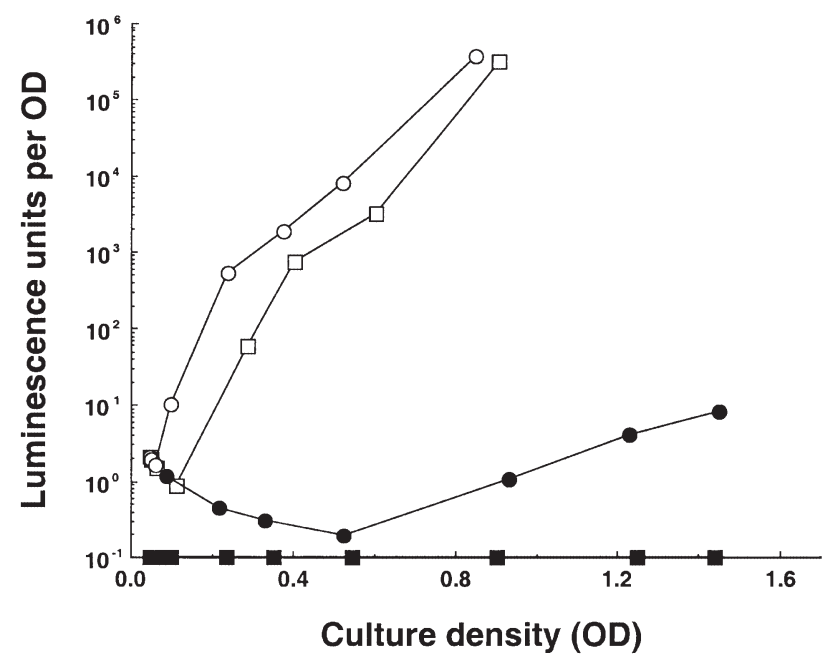

Fig. 5. Luminescence patterns of cells from $V$. fischeri strain ES114 (circles) and strain PMF8 (squares), grown in the presence (open symbols) or absence (closed symbols) of added VAI-1. One luminescence unit equals $1.3 \times 10^{4}$ quanta $\mathrm{s}^{-1} \mathrm{ml}^{-1}$.

findings suggest that litR, like opaR (McCarter, 1998), hapR (Jobling and Holmes, 1997) and smcR (Shao and Hor, 2001), may also control opacity. Opacity has also been associated with the ability of $V$. vulnificus to produce siderophores (Reddy et al., 1992). However, PMF8 showed no defect in its ability to sequester iron on CAS agar when compared with the parent strain (data not shown).

The litR homologues hapR and $s m c R$ have been reported to control protease production in $V$. cholerae (Jobling and Holmes, 1997) and V. vulnificus (McDougald et al., 2001; Shao and Hor, 2001) respectively. However, we were unable to detect any alteration in either protease or mucinase activities in strain PMF8 (data not shown). The protease activities of PMF8 and ES114 were equivalent, and both were reduced to undetectable levels by the addition of Zincov, suggesting that the major detectable extracellular agent of proteolysis in each of these strains is a zinc-requiring metalloprotease(s). Furthermore, overexpression of litR in a strain of $E$. coli carrying a hap promoter that controlled lacZ expression did

\begin{tabular}{llc}
\hline Test plasmid & Reporter plasmid & $\beta$-Galactosidase expression \\
\hline (None) & pJE455 (luxR::lacZ) & 7 \\
pMF7 (litR $R^{-}$; vector control) & pJE455 (luxR::lacZ) & 3 \\
pMF2 (litR ${ }^{+}$) & pJE455 (luxR::lacZ) & 121 \\
(None) & pJE413 (luxC::lacZ) & 7 \\
pMF7 (lit $R^{-} ;$vector control) & pJE413 (luxC::lacZ) & 8 \\
pMF2 (lit $\left.R^{+}\right)$ & pJE413 (luxC::lacZ) & 9 \\
\hline
\end{tabular}

Table 2. litR-enhanced expression of $\beta$ galactosidase from a $V$. fischeri luxR promoterreporter.

a. Fluorescence units per OD unit $\left(5 \times 10^{8}\right.$ cells $)$ above background; values are representative of three independent experiments. 
A

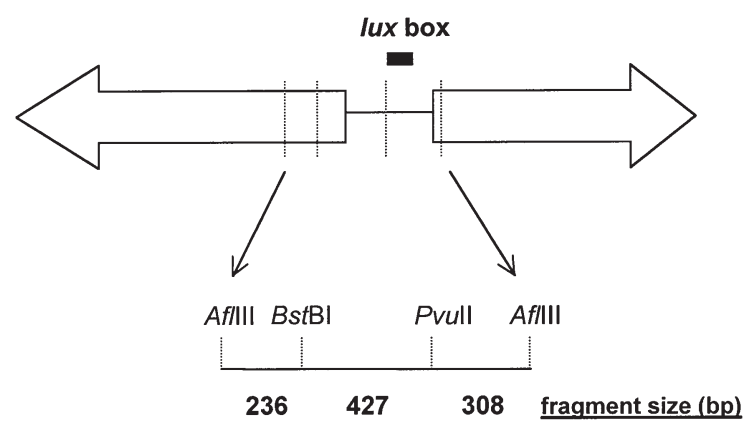

B

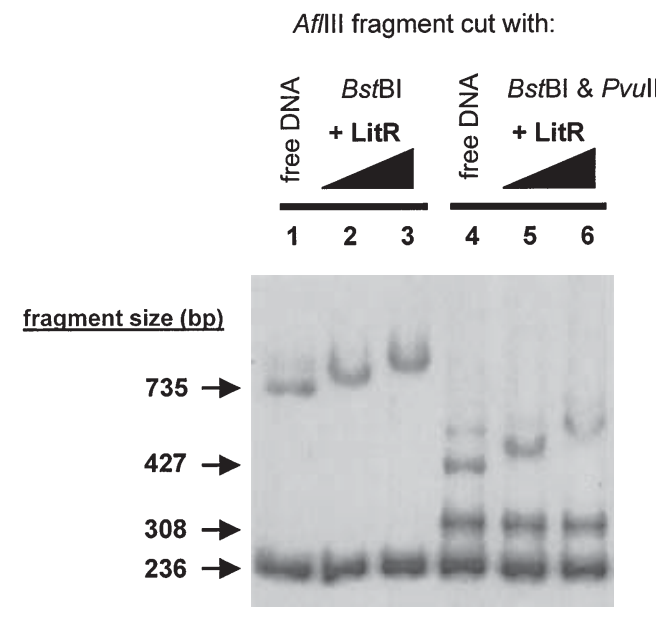

Fig. 6. Localization of the LitR binding site in the lux operon promoter region by mobility shift analysis.

A. An Aflll fragment encompassing the luxR-luxl intergenic region was isolated, digested with either BstBI or BstBI and Pvull and labelled with $\left.{ }^{32} \mathrm{P}\right]-\mathrm{dCMP}$.

B. The resulting DNA fragments were mixed with purified LitR (lanes 1 and 4, no LitR added; lanes 2 and $5,0.6 \mu \mathrm{g}$ of LitR added; lanes 3 and $6,0.8 \mu \mathrm{g}$ of LitR added) in the presence of poly-(dl-dC)/poly-(dl-dC) competitor DNA and subjected to electrophoresis in a $5 \%$ polyacrylamide gel. The migration of the $735 \mathrm{bp}$ (but not the $236 \mathrm{bp}$ ) DNA fragment (lanes 2 and 3), as well as that of the $427 \mathrm{bp}$ (but not the 236 or $308 \mathrm{bp}$ ) DNA fragment, apparently bound LitR and was retarded. A small amount of $663 \mathrm{bp}$ fragment, probably resulting from incomplete digestion by $B s t \mathrm{BI}$, is visible in lane 4.

not result in the induction of $\beta$-galactosidase activity (data not shown). Taken together, these data suggest that a mutation in litR does not affect protease production in $V$. fischeri, and that litR is not a functional homologue for this activity of $h a p R$. In addition to its potential role in protease regulation, $s m c R$ may also negatively regulate motility (McDougald et al., 2001). However, PMF8 and ES114 were equally motile when assayed in semi-solid agar (data not shown).

\section{Characterization of light organ colonization by the litR mutant}

The three criteria of efficiency, extent and competitiveness were used to assess the ability of the litR mutant to colonize the juvenile squid light organ. The colonization efficiency of strain PMF8 at low cell inocula was indistinguishable from its parent; that is $100 \%$ of juveniles became infected when they were exposed to sea water containing either strain at concentrations as low as 400 cells $\mathrm{ml}^{-1}$ (data not shown). Interestingly, although there was a $1 \mathrm{~h}$ delay in the onset of detectable luminescence, the levels of light emitted by these squids at 12, 24 and $48 \mathrm{~h}$ after infection were equivalent for both strains. These results indicated that the mutant was able to reach an essentially fully induced state in the light organ, even without a functioning litR gene.

The second criterion examined was the size of the symbiont population attained by each strain. At $24 \mathrm{~h}$ after infection, the average number of cfus present in light organs colonized by the parent strain $(2.3 \pm 0.7 \times$ $10^{5}$ ) was not significantly different from the number in mutant-colonized animals $\left(1.7 \pm 0.5 \times 10^{5}\right)$. This similarity was observed in the symbiotic populations of light organs after $48 \mathrm{~h}$ as well.

Thirdly, we determined whether either the parent or the mutant strain was able to outcompete the other when they simultaneously colonized the same light organ. Fortyeight hours after exposure of 21 juvenile squids to sea water containing a 1:1 mixture of ES114 and PMF8 cells, the litR mutant was the predominant symbiont isolated from $18(86 \%)$ of the light organs (Fig. 7). In a second experiment, the mutant again outcompeted its parent in $79 \%$ (11 out of 14 ) of the juvenile squid (data not shown). Thus, not only can the litR mutant colonize the juvenile light organ as well as the wild-type strain, but it also expresses a competitive advantage during at least the first $48 \mathrm{~h}$ after infection. Because neither strain exhibited a growth advantage when competed against the other in a mixed inoculum of SWT medium, some condition(s) specific to the light organ environment is apparently responsible for eliciting the differential effect.

\section{Discussion}

During colonization of host tissue, the expression of sets of bacterial genes can be under the control of specific transcriptional regulators (Cotter and DiRita, 2000). Although most of these regulators have been described in bacteria that initiate pathogenic infections, a few have been found to play a role in the more commonly occurring phenomena of benign bacterial colonization (van Rhijn and Vanderleyden, 1995; Graf and Ruby, 2000). We report here a gene encoding such a regulator in the symbiotic luminous bacterium $V$. fischeri. This gene, designated litR, is a member of a family of genes found in at least five other Vibrio species that are animal pathogens (Showalter et al., 1990; Jobling and Holmes, 1997; McCarter, 1998; Milton et al., 1999; McDougald 


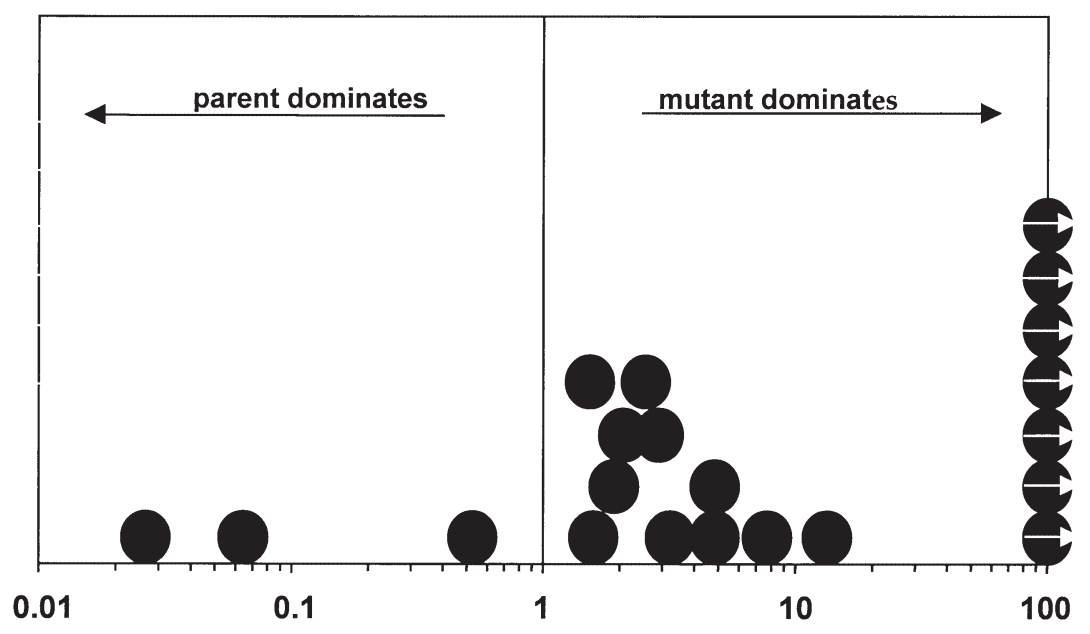

Fig. 7. Competition between the wild-type $V$. fischeri symbiont ES114 and its derivative, the litR mutant PMF8, during colonization of juvenile squid light organs. Twenty-one newly hatched squid were exposed to a mixed inoculum containing equal cell numbers of each strain. Forty-eight hours after the initial exposure to the bacterial inoculum, squid light organs were homogenized, and dilutions were spread on SWT agar medium. The ratio of mutant to parental bacterial strain in each light organ is expressed as the relative competitive index $(\mathrm{RCl})$ and is indicated by a circle. Circles with an arrow indicate an $\mathrm{RCl}$ of $>100$. An $\mathrm{RCl}$ above 1.0 indicates that the litR mutant cells were competitively dominant.

$\underline{\text { Relative competitive index (RCI) }}$

et al., 2000). Our studies with a litR mutant strain of $V$. fischeri have resulted in two discoveries: (i) a new level at which luminescence is regulated in this species; and (ii) a novel genotype that increases symbiotic competency.

Genetic analysis of the litR gene locus has revealed that it is flanked by gene homologues of hpt (upstream) and Ipd (downstream); these two genes also flank V. parahaemolyticus opaR and V. vulnificus smcR, and occur in the same orientation (McCarter, 1998; McDougald et al., 2000). The hpt gene is also found upstream of $V$. cholerae hap $R$ and $V$. harveyi lux $R$, but the downstream flanking genes in each of these species are not related either to Ipd or to each other (Jobling and Holmes, 1997). LitR shares about $60 \%$ identity to V. harveyi LuxR, V. cholerae HapR, V. parahaemolyticus OpaR and $V$. vulnificus SmcR. A comparison of the amino acid sequence of these homologues revealed several regions of particularly high identity, including the consensus HTH DNA-binding domain characteristic of the TetR family of negative transcriptional regulators (PROSITE accession number PS01081). Taken together, these similarities suggest that the homologues are derivatives of an ancestral gene that was acquired before these Vibrio species diverged (Fig. 3).

The high sequence similarity of these regulators suggested that they might be able to complement each other genetically. Previous work has shown that $V$. harveyi LuxR and $V$. cholerae HapR are functionally interchangeable (Jobling and Holmes, 1997) and, when carried in trans, either OpaR or SmcR could activate the expression of the $V$. harveyi lux operon in E. coli (McCarter, 1998). In the work reported here, expression of $V$. harveyi LuxR in trans alleviated the luminescence deficiency of strain PMF8 (Table 1). In contrast, expression of LitR in trans did not similarly restore luminescence to either $V$. harveyi strain MR1130 (lux $\left.R^{-}\right)$or an E. coli strain carrying plasmid
pRS205 ( $V$. harveyi luxR; luxCDABE'); in fact, cell growth was severely inhibited in transconjugants of both these strains (data not shown). These results are consistent with previous reports (Chatterjee et al., 1996), in which overexpression of $V$. harveyi lux $R$ in certain strains of $V$. harveyi and $E$. coli produced a cytotoxic affect, and suggested possible gene dosage effects on other unknown genes.

In most cases, the litR gene homologues in Vibrio species encode a protein that controls the expression of one or more phenotypes believed to be important in the successful colonization of animal tissue (e.g. motility, protease secretion, siderophore production, etc.). Interestingly, although there is some overlap in these phenotypes, the particular set of regulated genes is distinct in each species. In $V$. fischeri, a litR mutant has two distinct phenotypes in culture: (i) diminished luminescence, similar to but not as great as that of a $V$. harveyi lux $R$ mutant (Martin et al., 1989); and (ii) reduced colony opacity, like that of a $V$. parahaemolyticus opa $R$ mutant (McCarter, 1998).

The structure and regulation of the luminescence (lux) genes of $V$. fischeri have been the subjects of extensive investigation for over 25 years (Nealson, 1999). These genes are arranged as two divergent operons, with luxl$C D A B E$ comprising the rightward operon, and luxR (not a homologue of $V$. harveyi luxR) comprising the leftward operon (Engebracht and Silverman, 1987). The luxl product encodes the synthase of the primary $V$. fischeri autoinducer (VAl-1). The IUxC, IUxD and IUxE genes encode products necessary to synthesize an aliphatic aldehyde, a substrate for luciferase. The $\alpha$ and $\beta$ subunits of luciferase are encoded by IuxA and luxB respectively. In the intergenic sequence between IuxR and $|u x|$ is a regulatory region of about $150 \mathrm{bp}$ that contains a $20 \mathrm{bp}$ inverted repeat (called the lux box), to which $V$. fischeri 
LuxR binds when it is conjugated with VAl-1. The result of this binding is an enhanced transcription of the rightward operon and a concomitant induction of luminescence emission (Devine et al., 1989). LuxR and VAl-1 comprise the primary regulatory components modulating IuxICDABE expression (Sitnikov et al., 1995) and are required for the normal cell density-sensing luminescence response exhibited by $V$. fischeri in the squid light organ (Visick et al., 2000).

The $V$. harveyi LuxR protein does not use a quorumsensing cofactor in its regulation of luminescence gene expression, although a $V$. harveyi autoinducer has been reported to enhance the transcription of $V$. harveyi lux $R$ itself (Miyamoto et al., 1996). We propose a similarly direct mechanism to explain the regulation of luminescence by $V$. fischeri LitR. Mobility shift studies presented here support this hypothesis by identifying a region in the $V$. fischeri lux operon to which LitR can bind (Fig. 6). This region is located within a $427 \mathrm{bp}$ BstBI-Pvull DNA sequence that encompasses a portion of the $5^{\prime}$ end of $V$. fischeri luxR as well as $70 \mathrm{bp}$ of the luxR promoter region: the lux box is not included in this apparent LitR binding region (Fig. 6). Activation of the expression of a promoterless $\beta$-galactosidase gene fused to the $V$. fischeri luxR promoter (but not one fused to luxC) further indicated that LitR not only bound a region of DNA within the luxR promoter, but was also a positive regulator of that promoter's activity. It is important to note that LitR may have other more complex regulatory roles in $V$. fischeri: LitR homologues have been reported to express dual positive and negative regulatory roles for both luminescence control by V. harveyi LuxR (Chatterjee et al., 1996) and the modulation of protease (positive) and cytolysin (negative) expression by $V$. vulnificus SmcR (Shao and Hor, 2001).

Taken together, the following evidence supports a model in which LitR plays its greatest role in luminescence induction as a transcriptional activator of $V$. fischeri LuxR: (i) PMF8 is delayed in luminescence induction and reduced in luminescence level; (ii) this defect in luminescence behaviour was not fully alleviated by additions of aldehyde and/or VAl-1; (iii) LitR was able to bind a region of DNA that encompassed the $V$. fischeri lux $R$ promoter; and (iv) LitR activated expression of a reporter gene that was controlled by a $V$. fischeri luxR promoter fusion. As a result of LitR activating luxR expression, LuxR becomes available to bind to VAl-1 and induce the expression of IUXICDABE. When the ambient concentration of VAl-1 reaches a critical level, this mechanism for sensing cell density will dramatically induce the level of light production (Nealson, 1977).

In addition to the role in luminescence regulation played by both $V$. fischeri LitR and $V$. harveyi LuxR (Showalter et al., 1990), defects in protease activity, motility and/or siderophore production have also been associated with mutations in LitR homologues from several other Vibrio species (Reddy et al., 1992; Jobling and Holmes, 1997; McDougald et al., 2001). However, although V. fischeri cells normally express all these latter activities, a litR mutation apparently affects none of them. In contrast, LitR does seem to be involved in a fourth associated phenotype, the regulation of opacity; i.e. colonies of PMF8 were noticeably less opaque than those of the parent strain. In V. cholerae (Jobling and Holmes, 1997), V. parahaemolyticus (McCarter, 1998) and V. vulnificus (Reddy et al., 1992), colony opacity or rugosity is controlled by the presence of their LitR homologues and has been associated with the production of an extracellular polysaccharide. In $V$. vulnificus, opacity has also been correlated with an enhanced virulence resulting from the presence of an antiphagocytic capsular polysaccharide (Wright et al., 1990). Similarly, opaque strains of $V$. parahaemolyticus are reported to be more resistant to killing by oyster haemocytes (Genthner et al., 1999). When colonizing the squid, $V$. fischeri cells must face phagocytic host haemocytes in the light organ crypts (Nyholm and McFall-Ngai, 1998), a challenge that they avoid more effectively than other Vibrio species. It will be interesting to see whether the $V$. fischeri LitR mutant is more or less resistant to this particular host defence; i.e. is the surface chemistry associated with opacity a positive colonization factor for pathogens, but a negative one for co-operative infections?

Perhaps the most striking finding in this work is that, when squid were exposed to an inoculum containing equal cell numbers of both the mutant and the parent strain, PMF8 became the predominant cell type in the symbiont population. Although surprising, evidence for enhanced infection of a host by bacteria that are mutated for a particular wild-type activity is not without precedent (Campbell et al., 1998; Lee et al., 2001; Shao and Hor, 2001). Nevertheless, our data are unexpected in view of previous work showing that a knock-out mutation in the $V$. fischeri luxR gene, which is positively regulated by LitR (Table 3), results in both an inability to produce normal levels of luminescence in the light organ and a significantly decreased symbiont population size (Visick et al., 2000). Juvenile squid infected by PMF8 were as luminous at 12,24 and $48 \mathrm{~h}$ after initial infection as were those squids infected with the parent strain. Thus, even in the absence of LitR, luxR transcription and its eventual effect on induction of luminescence still occur. This conclusion is supported by a previous report that the level of VAl-1 in the light organ is over 40-fold higher than that required for maximal luminescence induction (Boettcher and Ruby, 1995), and data presented here showing that cells of 
Table 3. Bacterial strains and plasmids used in this study.

\begin{tabular}{|c|c|c|}
\hline Strain or plasmid & Genotype or relevant characteristics & Reference or source \\
\hline \multicolumn{3}{|l|}{ E. coli } \\
\hline $\mathrm{DH} 5 \mathrm{a}$ & V. fischeri luxR promoter::lacZ & Dunlap and Greenberg (1985) \\
\hline BL21 & T7 RNA polymerase, Ptac & Sturdier et al. (1990) \\
\hline \multicolumn{3}{|l|}{ V. fischeri } \\
\hline ES114 & E. scolopes light organ symbiont & Boettcher and Ruby (1990) \\
\hline PMF8 & ES114 derivative, litR::Kn & This study \\
\hline ES401 & E. scolopes light organ symbiont & This study \\
\hline EM17 & E. morsei light organ symbiont & Nishiguchi et al. (1998) \\
\hline EM24 & E. morsei light organ symbiont & Nishiguchi et al. (1998) \\
\hline MJ1 & Monocentris japonica symbiont & Ruby and Nealson (1976) \\
\hline ATCC 7744 & V. fischeri type strain & American Type Culture Collection \\
\hline H905 & Hawaii sea-water isolate & Lee and Ruby (1994) \\
\hline H906 & Hawaii sea-water isolate & Lee and Ruby (1994) \\
\hline \multicolumn{3}{|l|}{ V. logei } \\
\hline MdR16 & S. California sea water & Fidopiastis et al. (1998) \\
\hline MdRD & S. California sea water & Fidopiastis et al. (1998) \\
\hline \multicolumn{3}{|l|}{ V. harveyi } \\
\hline B392 & Sea-water isolate & Reichelt and Baumann (1973) \\
\hline MR1130 & B392 derivative, lux $R$ null mutant & Showalter et al. (1990) \\
\hline \multicolumn{3}{|l|}{ Plasmid } \\
\hline $\mathrm{pKSII}^{+}$ & Bluescript, $A p^{R}$ resistance & Stratagene \\
\hline pVO8 & pACYC with $\mathrm{Cm}^{\mathrm{R}}, \mathrm{Em}^{\mathrm{R}}$ & Visick and Ruby (1997) \\
\hline pJE413 & pBR322 with luxC::mini-Mu, $\mathrm{Kn}^{\mathrm{R}}$ & Dunlap and Greenberg (1985) \\
\hline pJE455 & pBR322 with luxR::mini-Mu, $\mathrm{Kn}^{\mathrm{R}}$ & Dunlap and Greenberg (1985) \\
\hline pUC4K & $\mathrm{Kn}^{\mathrm{R}}$ on $1.2 \mathrm{~kb} \mathrm{BamHI}$ fragment & Vieira and Messing (1982) \\
\hline pEVS79 & $\mathrm{pBC}$ derivative, $\mathrm{mob}^{+}, \mathrm{Cm}^{\mathrm{R}}$ & Stabb and Ruby (2002) \\
\hline pMGM150 & V. harveyi luxR on pKT230, $\mathrm{Sm}^{\mathrm{R}}$ & Miyamoto et al. (1990) \\
\hline pMF2 & lith on $1 \mathrm{~kb}$ fragment, $\mathrm{pVO}, \mathrm{Cm}^{\mathrm{R}}$ & This study \\
\hline pMF6 & litR on $3 \mathrm{~kb}$ Sacl-Clal fragment in pEVS79, $\mathrm{Cm}^{\mathrm{R}}$ & This study \\
\hline pMF7 & pMF6, litR::Kn, $\mathrm{Cm}^{\mathrm{R}}$ & This study \\
\hline pRS205 & V. harveyi luxCDABE & Showalter et al. (1990) \\
\hline pQF3.1 & V. cholerae hap promoter::lacZ & Jobling and Holmes (1997) \\
\hline $\mathrm{pC} 1.1$ & V. cholerae hapR gene & Jobling and Holmes (1997) \\
\hline pCR2.1 & Cloning vector, $\mathrm{Ap}^{\mathrm{R}}, \mathrm{Cm}^{\mathrm{R}}$ & Invitrogen \\
\hline
\end{tabular}

PMF8 growing in culture medium containing VAI-1 rapidly attained levels of luminescence that were only slightly below those reached by the parent strain (Fig. 5). The result is that there is no evidence that the role of LitR in luminescence induction has a significant role in symbiotic colonization.

What then might be the basis of the competitive advantage expressed by the $V$. fischeri litR mutant? The altered opacity of colonies produced by strain PMF8 suggested that this strain might have a different cell surface chemistry. Thus, we hypothesized that such a difference might allow the mutant to adhere to the walls of the light organ crypt more effectively than its wild-type parent. Because $\approx 95 \%$ of the symbiotic cells in the light organ are expelled each morning (Lee and Ruby, 1994a), an initially mixed (wild type + litR mutant) population might eventually tend towards dominance by the mutant. When this hypothesis was tested by examining the ratio of mutant and wild-type cells present in the light organ before and after an expulsion event, no evidence for a differential adherence was detected (data not shown). Thus, the mechanism underlying the competitive advantage of the litR mutant, at least during the first few days of colonization, must await future efforts, such as the identification of the genetic loci that LitR regulates. Perhaps a more complete model for LitR-mediated transcriptional activation in $V$. fischeri will provide important clues to how the critical balance that is required for an animal host and its bacterial symbionts maintains a persistent benign infection.

\section{Experimental procedures}

\section{Bacterial strains, plasmids and growth media}

The Vibrio spp. strains and E. coli strains and plasmids used in this study are listed in Table 3. All strains were stored at $-70^{\circ} \mathrm{C}$ until needed. $V$. fischeri strains were grown in a sea water-tryptone-yeast extract medium (SWT) as described previously (Boettcher and Ruby, 1990). Measurements of culture luminescence were performed in this medium rather than in a conditioned medium (Boettcher and Ruby, 1995) to exclude any possible influence of the $V$. harveyi luxS auto- 
inducer. Antibiotics were used at the following concentrations: ampicillin (Ap) $100 \mu \mathrm{g} \mathrm{ml}^{-1}$; chloramphenicol (Cm) $30 \mathrm{\mu g} \mathrm{ml}^{-1}$; kanamycin $(\mathrm{Kn}) 100 \mathrm{gg} \mathrm{ml}^{-1}$; and streptomycin (Sm) $50 \mu \mathrm{g} \mathrm{ml}^{-1}$. Xgal indicator was used in Luria-Bertani (LB) agar medium at $40 \mu \mathrm{g} \mathrm{ml}^{-1}$.

\section{$P C R$, cloning and sequencing of $\mathrm{V}$. fischeri litR}

Cells of $V$. fischeri strain ES114 were grown with shaking in SWT medium at $28^{\circ} \mathrm{C}$ overnight to an optical density (OD) at $600 \mathrm{~nm}$ of between 1.0 and 1.2 (Boettcher and Ruby, 1990). Cells were collected by centrifugation, and genomic DNA was extracted using the GNome DNA kit (Bio101) in accordance with manufacturer's instructions. An aliquot containing 100-200 ng of $V$. fischeri genomic DNA was mixed with PCR primers to amplify litR in a PCR as described previously (Fidopiastis et al., 1998). The following degenerate PCR primers were used to detect first the $V$. fischeri hap $R$ homologue: VchapR-deg5 (forward) 5' GGN ATN GGN CGN GGN GGN CAY GCN GA 3' and VchapR-deg3 (reverse) 5' CCA YTC RAA CCA NAC YTT NAR CCA 3'. PCR primers Vf litRf (forward) 5' GGC ATT GGT GGC GGT GGT CAT GCT GA $3^{\prime}$ and Vf litRr (reverse) 5' CCA TTC AAA CCA TAC TTT GAT CCA $3^{\prime}$ were designed based on the sequence of the homologous product and used to locate the litR gene within a $12 \mathrm{~kb}$ fragment carried in a plasmid library of EcoRI-cut $V$. fischeri genomic DNA. The litR locus was localized on the fragment and sequenced. Using this sequence, PCR primers $V f$ litRdf (forward): 5' GAT TAA GGA AGA GCT GTT AAC GG 3'; and Vf litRdr (reverse): 5' GCT GCG GAA GTA TTT GAA GG $3^{\prime}$ were designed to amplify $1 \mathrm{~kb}$ of DNA containing the entire litR gene with additional flanking genomic DNA. PCR products were ligated into the vector pCR2.1 and cloned into E. coli using the TA cloning kit (Invitrogen). The $1 \mathrm{~kb}$ PCR product was cut from pCR2.1 with EcoRI and ligated into the mobilizable vector pVO8 (Visick and Ruby, 1997) to create pMF2 (lit $\left.R^{+}\right)$. Plasmid DNA was purified from several $E$. coli clones using the Perfect Prep plasmid kit (5 prime-3 prime), cut with the appropriate restriction enzymes and loaded into separate wells of a $1 \%$ agarose gel. Inserts of the predicted size were sequenced at the Biotechnology Molecular Biology Instrumentation Facility, University of Hawai'i, Manoa. Double-stranded sequence of the litR coding region and single-stranded sequence of flanking DNA extending into the neighbouring upstream and downstream genes were obtained by primer walking. Sequence data were analysed using DNA STRIDER version 1.2, BLAST (Altschul et al., 1990) and VECTOR NTI SUITE software (InforMax). The nucleotide sequence of the $606 \mathrm{bp}$ litR coding region has been submitted to the GenBank databases under accession number AF378100.

\section{Mobility shift assays}

Production and partial purification of $V$. fischeri LitR and $V$. harveyi LuxR proteins were performed using a previously described protocol (Swartzman and Meighen, 1993). Plasmids (encoding Ap resistance) containing litR or luxR under T7 promoter control were transformed into $E$. coli BL21 (DE3), a strain with T7 RNA polymerase encoded within the chromosome under IPTG-inducible control. The recombinant
E. coli strains were inoculated to an OD of 0.05 in LB medium containing Ap and grown at $37^{\circ} \mathrm{C}$. At an OD of 0.5 , IPTG was added to a final concentration of $1 \mathrm{mM}$ to induce $\mathrm{T} 7$ polymerase and thereby overexpress the plasmid-encoded gene products. After the cultures had reached an OD of between 1 and 2, the cells were harvested by centrifugation. One hundred microlitres of lysis buffer (Swartzman and Meighen, 1993) was added to a pellet containing about $10^{9}$ cells, and the suspension was disrupted with a Branson ultrasonicator at a setting of 30 , using three $10 \mathrm{~s}$ treatments. Cellular debris was removed by centrifugation, and the protein content in the lysis supernatants was estimated spectrophotometrically. Mobility shift assays were performed with the lysates according to established procedures (Fried and Crothers, 1981; Swartzman and Meighen, 1993), using restricted V. fischeri DNA as the binding target.

\section{Mutation of litR}

The litR gene was centred within a $5 \mathrm{~kb} P s t-S a c l$ fragment of DNA from the EcoRI-cut $V$. fischeri genomic library, which was subcloned into pBluescript KS (Stratagene), creating plasmid pMF5. The litR gene and flanking DNA from pMF5 was moved into the mobilizable vector pEVS79 (Stabb and Ruby, 2002) as follows. The two vectors were digested with Clal, then fused by ligating the two major fragments produced. This hybrid plasmid was restricted with Sacl and selfligated to remove a $3 \mathrm{~kb}$ fragment of unnecessary DNA. The resulting vector, pMF6, carried litR on a $3 \mathrm{~kb}$ Sacl-Clal fragment. The litR gene in pMF6 was then disrupted by the insertion of a $1.2 \mathrm{~kb} B a m \mathrm{HI}$ fragment encoding the kanamycin marker from pUC4K (Vieira and Messing, 1982) into a unique $B g / l$ site located 180 bases downstream of the predicted litR start codon, creating pMF7

The mutant allele was then introduced into the $V$. fischeri ES114 chromosome by triparental conjugation as described previously (Stabb et al., 2001). The addition of chloramphenicol to growth media selected for single recombination events between pMF7 and the $V$. fischeri genome. Double recombinants that arose upon subsequent transfer, and that no longer retained vector sequences, were identified by both their chloramphenicol sensitivity and stable expression of kanamycin resistance (Visick and Ruby, 1996). The presence of the mutant allele in the chromosome of recombinant strain PMF8 was confirmed by PCR using primer sets Vf litRf and $\mathrm{Vf}$ litRr, or Vf litRdf and Vf litRdr, which both flank the site of kanamycin gene insertion.

\section{Functional complementation of the litR mutation}

Plasmid pMF2 (lit $R^{+}$) or its parent vector pVO8 were electroporated into $E$. coli strains carrying reporter plasmids in which promoters of either hap (pQF3.1) (Jobling and Holmes, 1997) or V. fischeri luxR (Dunlap and Greenberg, 1985) drive lacZ expression. Plasmid pMF2 was also electroporated into an E. coli strain carrying pRS205 ( $V$. harveyi luxR; l luxCDABE'; Showalter et al., 1990) or conjugated (as described previously) into $V$. fischeri luxR and luxI mutants (Visick et al., 2000), and the level of luminescence of the resultant strains was determined. Electroporation was performed at $2.5 \mathrm{kV}$ and $400 \Omega$ using a GenePulser apparatus (Bio-Rad). Lumi- 
nescence reporters were also used to determine the role of litR. Plasmid pPMF2 was electroporated into an E. coli strain carrying pRS205 or conjugated (Stabb et al., 2001) into $V$. fischeri luxl and luxR mutants (Visick et al., 2000) before luminescence measurement. E. coli reporter strains were streaked on LB agar medium with the appropriate antibiotics to maintain the plasmids and incubated overnight at $37^{\circ} \mathrm{C}$. Confluently growing cells from the plates were scraped and added to separate microfuge tubes. Cells were washed three times in $10 \%$ glycerol and resuspended in $100 \mu \mathrm{l}$ of $10 \%$ glycerol to which vector ( $\mathrm{pVO} 8)$, a positive control ( $\mathrm{pC} 1.1$, hapR $\left.{ }^{+}\right)$ (Jobling and Holmes, 1997) or pMF2 was added just before electroporation. Colonies expressing the appropriate antibiotic resistances were expected to contain both the reporter and the experimental plasmids. The presence of pMF2 in the appropriate E. coli strains was confirmed by PCR.

The results of litR complementation experiments with the hap promoter reporter were indicated by the blue or white colour of colonies arising on LB agar medium supplemented with Xgal and the appropriate antibiotics. Confirmation of complementation of the $V$. fischeri luxR promoter reporter was performed using the Ima Gene Green C12 FDG lacZ gene expression kit (Molecular Probes), according to the manufacturer's instructions. Fluorescence emission was measured using an HTS 7000 fluorimeter (Perkin-Elmer). To determine their effects on light production in either $V$. fischeri or $V$. harveyi, plasmids pMF2 and pMGM150 ( $V$. harveyi lux $R^{+}$; Miyamoto et al., 1996) were conjugated into the recipient Vibrio species as described previously (Stabb et al., 2001). The resulting strains were grown in SWT broth, and their levels of luminescence were determined at an OD of 1.0 .

\section{Bacterial bioluminescence assays}

The level of bacterial luminescence in culture, with or without either exposure to $3 \mathrm{mM}$ decyl aldehyde (decanal) or the addition of the $V$. fischeri autoinducer, 3-oxohexanoyl Lhomoserine lactone (VAl-1) to a concentration of $200 \mathrm{ng} \mathrm{ml}^{-1}$, was determined as described previously (Fidopiastis et al., $1998 ; 1999)$. Bacterial strains were inoculated to an OD of 0.01 in flasks containing $15 \mathrm{ml}$ of SWT medium and grown with shaking at either $22^{\circ} \mathrm{C}$ or $28^{\circ} \mathrm{C}$. The $\mathrm{OD}$ and luminescence of aliquots of the cultures were measured at regular intervals throughout the exponential phase of growth.

\section{Colony appearance, protease activity, siderophore production and motility}

The protease activities of $V$. fischeri strains ES114 and PMF8 were determined using cells grown either on solid medium or in broth culture. Protease activity on plates was assayed by streaking bacterial strains on a basal medium consisting of $50 \mathrm{mM}$ Tris- $\mathrm{HCl}$ buffer (pH 7.4), $340 \mu \mathrm{M} \mathrm{K}_{2} \mathrm{HPO}_{4}$ and $15 \mathrm{~g}$ of agar per litre of artificial sea water (Reichelt and Baumann, 1973) to which $10 \mathrm{~g}$ of porcine mucin (Sigma Chemical) were added per litre as the sole carbon and nitrogen source. After inoculation, plates were incubated for up to $96 \mathrm{~h}$ at $28^{\circ} \mathrm{C}$ and then flooded with a $15 \% \mathrm{HgCl}_{2}$ solution (acidified with $\mathrm{HCl}$ ) and incubated overnight. This overlying solution was then replaced with a $1 \%$ aqueous Coomassie blue stain and incu- bated overnight again. When the stain solution was removed, the absence of a blue colour staining in the medium around the area of bacterial growth indicated the extent of mucin digestion. Protease activity was also assayed on cells grown to exponential phase with shaking in SWT medium. An aliquot of cells was mixed in a reaction buffer $(200 \mathrm{mM}$ Tris- $\mathrm{HCl}$, $\mathrm{pH} 7.8$ ) containing $2 \mathrm{mM}$ sodium azide and $5 \mu \mathrm{M}$ L-leucine 7-amido-4-methyl-coumarin protease substrate (Sigma Chemical). At intervals of $8 \mathrm{~min}$, fluorescence emission by the product of the proteolytic cleavage of this substrate was determined in the HTS 7000 fluorimeter. Some of the reactions also contained $500 \mu \mathrm{M}$ Zincov (CalBiochem), a specific zinc-metalloprotease inhibitor.

Siderophore production was determined by streaking strains on an agar medium containing the iron-chelation indicator chrome azurol S (CAS), prepared as described previously (Lee and Ruby, 1994b). The degree of motility of bacterial strains was determined by stabbing cells into SWT medium solidified with $0.4 \%$ agar and monitoring over time the diameter of the halo of migrating cells moving outwards from the point of inoculation.

\section{Colonization assays}

The ability of the $V$. fischeri litR mutant strain to colonize juvenile E. scolopes squid was determined as described previously (Ruby and Asato, 1993). Briefly, cells of PMF8 and ES114 were inoculated into natural sea water to concentrations of between 400 and 2200 cells ml$^{-1}$, either as the individual strains or as a 1:1 mixture of the two. Newly hatched, uninfected (aposymbiotic) juvenile squid were then placed in this sea water and maintained at $22^{\circ} \mathrm{C}$ for up to $48 \mathrm{~h}$. The colonization process was monitored at 12,24 and $48 \mathrm{~h}$ after initial exposure to the bacteria by measuring the amount of bacterial bioluminescence emitted from the squid. At either 24 or $48 \mathrm{~h}$ after initial exposure to the bacteria, squid light organs were homogenized and plated on SWT agar. Total colony-forming-units (cfu) were calculated and, if the light organs had been colonized by a mixture of the two strains, about 100 colonies were patched onto both LBS agar and LBS agar containing $\mathrm{Kn}$ to determine the ratio of litR mutant to wild-type cells in each light organ. This ratio was then divided by the ratio (usually between 1.0 and 1.2) of mutant to wild type in the inoculum used to infect squid, and the resulting value was termed the mutant's relative competitive index $(\mathrm{RCl})$.

\section{Acknowledgements}

We thank C. Lupp for help with several experiments, and K. Visick, D. Millikan and E. Stabb for valuable advice and technical assistance throughout the course of this study. M. Urbanowski generously provided the plasmid pJE413. This work was supported by National Institutes of Health grant RR12294 to E.G.R. and M. McFall-Ngai, and by National Science Foundation grant IBN 9904601 to M. McFall-Ngai and E.G.R.

\section{References}

Altschul, S.F., Gish, W., Miller, W., Meyers, E.W., and 
Lipmann, D.J. (1990) Basic local alignment search tool. $J$ Mol Biol 215: 403-410.

Boettcher, K.J., and Ruby, E.G. (1990) Depressed light emission by symbiotic Vibrio fischeri of the sepiolid squid Euprymna scolopes. J Bacteriol 172: 3701-3706.

Boettcher, K.J., and Ruby, E.G. (1994) Occurrence of plasmid DNA in the sepiolid squid symbiont Vibrio fischeri. Curr Microbiol 29: 279-286.

Boettcher, K.J., and Ruby, E.G. (1995) Detection and quantification of Vibrio fischeri autoinducer from symbiotic squid light organs. J Bacteriol 177: 1053-1058.

Campbell, E.L., Brahamsha, B., and Meeks, J.C. (1998) Mutation of an alternative sigma factor in the cyanobacterium Nostoc punctiforme results in increased infection of its symbiotic plant partner, Anthoceros punctatus. $J$ Bacteriol 180: 4938-4941.

Chatterjee, J., Miyamoto, C.M., and Meighen, E.A. (1996) Autoregulation of luxR: the Vibrio harveyi lux-operon activator functions as a repressor. Mol Microbiol 20: 415425.

Cotter, P.A., and DiRita, V.J. (2000) Bacterial virulence gene regulation: an evolutionary perspective. Annu Rev Microbiol 54: 519-565.

Devine, J.H., Shadel, G.S., and Baldwin, T.O. (1989) Identification of the operator of the lux regulon from Vibrio fischeri ATCC 7744. Proc Natl Acad Sci USA 86: 56885692.

Dunlap, P.V., and Greenberg, E.P. (1985) Control of Vibrio fischeri luminescence gene expression in Escherichia coli by cyclic AMP and cyclic AMP receptor protein. J Bacteriol 164: 45-50.

Engebracht, J., and Silverman, M. (1987) Nucleotide sequence of the regulatory locus controlling expression of bacterial genes for bioluminescence. Nucleic Acids Res 15: 10455-10467.

Fidopiastis, P.M., and Ruby, E.G. (1999) The role of the homologue of the Vibrio cholerae hapR gene in the symbiotic colonization of a squid by Vibrio fischeri. Abstr Gen Meet Am Soc Microbiol 99: 461-462.

Fidopiastis, P.M., von Boletzky, S., and Ruby, E.G. (1998) A new niche for Vibrio logei, the predominant light organ symbiont of squids in the genus Sepiola. J Bacteriol 180: 59-64.

Fidopiastis, P.M., Sørum, H., and Ruby, E.G. (1999) Cryptic luminescence in the cold-water fish pathogen Vibrio salmonicida. Arch Microbiol 171: 205-209.

Finkelstein, R.A., Boesman-Finkelstein, M., and Holt, P. (1983) Vibrio cholerae hemagglutinin/lectin/protease hydrolyzes fibronectin and ovomucin: F. M. Burnet revisited. Proc Natl Acad Sci USA 80: 1092-1095.

Fried, M.G., and Crothers, D.M. (1981) Equilibria and kinetics of lac repressor-operator interactions by polyacrylamide gel electrophoresis. Nucleic Acids Res 9: 6505-6525.

Garcia, T., Otto, K., Kjelleberg, S., and Nelson, D.R. (1997) Growth of Vibrio anguillarum in salmon intestinal mucus. Appl Environ Microbiol 63: 1034-1039.

Genthner, F.J., Volety, A.K., Oliver, L.M., and Fischeri, W.S. (1999) Factors influencing in vitro killing of bacteria by hemocytes of the Eastern oyster (Crassostrea virginica) Appl Environ Microbiol 65: 3015-3020.
Graf, J., and Ruby, E.G. (1998) Host-derived amino acids support the proliferation of symbiotic bacteria. Proc Natl Acad Sci USA 95: 1818-1822.

Graf, J., and Ruby, E.G. (2000) Novel effects of a transposon insertion in the Vibrio fischeri glnD gene: defects in iron uptake and symbiotic persistence in addition to nitrogen utilization. Mol Microbiol 37: 168-179.

Hooper, L.V., and Gordon, J.I. (2001) Commensal hostbacterial relationships in the gut. Science 292: 1115-1118.

Jobling, M.G., and Holmes, R.K. (1997) Characterization of hapR, a positive regulator of the Vibrio cholerae $\mathrm{HA} /$ protease gene hap, and its identification as a functional homologue of the Vibrio harveyi luxR gene. Mol Microbiol 26: 1023-1034.

Lamarcq, L.H., and McFall-Ngai, M.J. (1998) Induction of a gradual, reversible morphogenesis of its host's epithelial brush border by Vibrio fischeri. Infect Immun 66: 777-785.

Lee, K.H., and Ruby, E.G. (1994a) Effect of the squid host on the abundance and distribution of symbiotic Vibrio fischeri in nature. Appl Environ Microbiol 60: 1565-1571.

Lee, K.H., and Ruby, E.G. (1994b) Competition between Vibrio fischeri strains during initiation and maintenance of a light organ symbiosis. J Bacteriol 176: 1985-1991.

Lee, S.H., Butler, S.M., and Camilli, A. (2001) Selection for in vivo regulators of bacterial virulence. Proc Natl Acad Sci USA 98: 6889-6894.

McCarter, L.L. (1998) OpaR, a homolog of Vibrio harveyi LuxR, controls opacity of Vibrio parahaemolyticus. $J$ Bacteriol 180: 3166-3177.

McDougald, D., Rice, S.A., and Kjelleberg, S. (2000) The marine pathogen Vibrio vulnificus encodes a putative homologue of the Vibrio harveyi regulatory gene, luxR: a genetic and phylogenetic comparison. Gene 248: 213-221.

McDougald, D., Rice, S.A., and Kjelleberg, S. (2001) SmcRdependent regulation of adaptive phenotypes in Vibrio vulnificus. J Bacteriol 183: 758-762.

McFall-Ngai, M. (1990) Crypsis in the pelagic environment. Am Zool 30: 175-188.

McFall-Ngai, M.J. (1994) Evolutionary morphology of a squid symbiosis. Am Zool 34: 554-561.

McFall-Ngai, M.J. (1999) Consequences of evolving with bacterial symbionts: insights from the squid-vibrio associations. Annu Rev Ecol Syst 30: 235-256.

Martin, M., Showalter, R., and Silverman, M.R. (1989) Identification of a locus controlling expression of luminescence genes in Vibrio harveyi. J Bacteriol 171: 2406-2414.

Milton, D., Hope, V., Camara, M., and Williams, P. (1999) Metalloprotease production in Vibrio anguillarum is regulated by VanS, a homolog of Vibrio harveyi LuxR. Abstr Gen Meet Am Soc Microbiol 99: 366.

Miyamoto, C.M., Meighen, E.A., and Graham, A.F. (1990) Transcriptional regulation of lux genes transferred into Vibrio harveyi. J Bacteriol 172: 2046-2054.

Miyamoto, C.M., Chatterjee, J., Swartzman, E., Szittner, R., and Meighen, E.A. (1996) The role of lux autoinducer in regulating luminescence in Vibrio harveyi: control of luxR expression. Mol Microbiol 19: 767-775.

Nealson, K.H. (1977) Autoinduction of bacterial luciferase: occurrence, mechanism, and significance. Arch Microbiol 112: 73-79. 
Nealson, K.H. (1999) Early observations defining quorumdependent gene expression. In Cell-Cell Signaling in Bacteria. Dunny, G.M., and Winans, S.C. (eds). Washington, DC: American Society for Microbiology Press, pp. 277289.

Nishiguchi, M.K., Ruby, E.G., and McFall-Ngai, M.J. (1998) Competitive dominance among strains of luminous bacteria provides an unusual form of evidence for parallel evolution in Sepiolid squid-vibrio symbioses. Appl Environ Microbiol 64: 3209-3213.

Nishina, Y., Miyoshi, S., Nagase, A., and Shinoda, S. (1992) Significant role of an exocellular protease in utilization of heme by Vibrio vulnificus. Infect Immun 60: 2128-2132.

Nyholm, S.V., and McFall-Ngai, M.J. (1998) Sampling the microenvironment of the Euprymna scolopes light organ: description of a population of host cells with the bacterial symbiont Vibrio fischeri. Biol Bull 195: 89-97.

Nyholm, S.V., Stabb, E.V., Ruby, E.G., and McFall-Ngai, M.J. (2000) Establishment of an animal-bacterial association: recruiting symbiotic vibrios from the environment. Proc Natl Acad Sci USA 97: 10231-10235.

Reddy, G.P., Hayat, U., Abeygunawardana, C., Fox, C., Wright, A.C., Maneval, D.R., et al. (1992) Purification and determination of the structure of capsular polysaccharide of Vibrio vulnificus M06-24. J Bacteriol 174: 26202630.

Reichelt, J.L., and Baumann, P. (1973) Taxonomy of the marine, luminous bacteria. Arch Mikrobiol 94: 283-330.

van Rhijn, P., and Vanderleyden, J. (1995) The Rhizobiumplant symbiosis. Microbiol Rev 59: 124-142.

Ruby, E.G., and Asato, L.M. (1993) Growth and flagellation of Vibrio fischeri during initiation of the sepiolid squid light organ symbiosis. Arch Microbiol 159: 160-167.

Ruby, E.G., and Nealson, K.H. (1976) Symbiotic association of Photobacterium fischeri with the marine luminous fish Monocentris japonica; a model of symbiosis based on bacterial studies. Biol Bull 151: 574-586.

Saitou, N., and Nei, M. (1987) The neighbor-joining method: a new method for reconstructing phylogenetic trees. $\mathrm{Mol}$ Biol Evol 4: 406-425.

Shao, C.-P., and Hor, L.-I. (2001) Regulation of metalloprotease gene expression in Vibrio vulnificus by a Vibrio harveyi LuxR homologue. J Bacteriol 183: 1369-1375.

Showalter, R.E., Martin, M.O., and Silverman, M.R. (1990) Cloning and nucleotide sequence of $l u x R$, a regulatory gene controlling bioluminescence in Vibrio harveyi. $J$ Bacteriol 172: 2946-2954.

Sitnikov, D.M., Schineller, J.B., and Baldwin, T.O. (1995) Transcriptional regulation of bioluminescence genes from Vibrio fischeri. Mol Microbiol 17: 801-812.

Stabb, E.V., and Ruby, E.G. (2002) New RP4-based plasmids for conjugation between Escherichia coli and members of the Vibrionaceae. Methods Enzymol (in press).

Stabb, E.V., Reich, K.A., and Ruby, E.G. (2001) Vibrio fischeri genes $h v n A$ and $h v n B$ encode secreted $N^{\prime} A D^{+}$-glycohydrolases. J Bacteriol 183: 309-317.

Sturdier, F.W., Rosenberg, A.H., Dunn, J.J., and Dubenhoff, J.W. (1990) The use of T4 RNA polymerase to direct expression of cloned genes. Methods Enzymol 185: 60-89.

Swartzman, E., and Meighen, E.A. (1993) Purification and characterization of poly (dA-dT) lux-specific DNA-binding protein from Vibrio harveyi and identification as LuxR. $J$ Biol Chem 268: 16706-16716.

Vieira, J., and Messing, J. (1982) The pUC plasmids, an M13mp7-derived system for insertion mutagenesis and sequencing with synthetic universal primers. Gene 19: 259-268.

Visick, K.L., and McFall-Ngai, M.J. (2000) An exclusive contract: specificity in the Vibrio fischeri-Euprymna scolopes partnership. J Bacteriol 182: 1779-1787.

Visick, K.L., and Ruby, E.G. (1996) Construction and symbiotic competence of a luxA-deletion mutant of Vibrio fischeri. Gene 175: 89-94.

Visick, K.L., and Ruby, E.G. (1997) New genetic tools for use in the marine bioluminescent bacterium Vibrio fischeri. In Bioluminescence and Chemiluminescence. Hastings, J.W., Kricka, L.J., and Stanley, P.E. (eds). New York: John Wiley and Sons, pp. 119-122.

Visick, K.L., Foster, J., Doino, J., McFall-Ngai, M., and Ruby, E.G. (2000) Vibrio fischeri lux genes play an important role in colonization and development of the host light organ. $J$ Bacteriol 182: 4578-4586.

Welch, T.J., and Bartlett, D.H. (1998) Identification of a regulatory protein required for pressure-responsive gene expression in the deep-sea bacterium Photobacterium species strain SS9. Mol Microbiol 27: 977-985.

Wright, L., Simpson, L.M., Oliver, J.D., and Morris, J.G. (1990) Relation of capsular materials and colony opacity to virulence of Vibrio vulnificus. Infect Immun 47: 446-451. 